\title{
Modos de ruptura e padrões de fissuração de vigas pré-moldadas de concreto armado geopolimérico: Estudo de caso
}

\section{Failure modes and cracking patterns of precasting geopolymer reinforced concrete beams: Case Study}

Eliane Fernandes Côrtes Pires ${ }^{1}$, Cláudio Mesquita Coutinho de Azevedo ${ }^{1}$ Elie Chahdan Mounzer ${ }^{2}$, Felipe José da Silva ${ }^{1,3}$, Fathi Aref Ibrahim Darwish ${ }^{1}$

\footnotetext{
${ }^{1}$ Departamento de Eng ${ }^{\text {a }}$ Civil, Universidade Federal Fluminense, Campus Praia Vermelha, Niterói, RJ, CEP 24210-240 e-mail: elianefcp@id.uff.br

${ }^{2}$ Departamento de Eng ${ }^{a}$ de Produção, Universidade Federal Fluminense, PURO, Rio das Ostras, RJ, CEP 28890-000

${ }^{3}$ Instituto Federal de Educação, Ciência e Tecnologia do Rio de Janeiro, Campus Paracambi, RJ, CEP 26600-000

e-mails: emounzer@yahoo.com.br, felipe.silva@ifrj.edu.br, fathi@uff.br
}

\section{RESUMO}

Esse trabalho apresenta um estudo comparativo do comportamento mecânico de vigas pré-moldadas de concreto armado convencional (CCP), fabricadas por uma empresa local e de concretos geopolimérico de metacaulim (CCG) e geopolimérico com $20 \%$ de cinza volante e silicato de cinza de casca de arroz (CCG-20CVCCA), como matrizes substitucionais. Os resultados mostraram que os concretos geopoliméricos apresentaram comportamento similar ao do CCP, na mesma classe de resistência do concreto, taxa de armadura e disposição das armaduras no elemento estrutural estudado. $\mathrm{O}$ uso das cinzas promoveu aumento do módulo de rigidez à flexão e dos limites de deformação das vigas geopoliméricas, em especial para a CCG-20CV-CCA sob a maior taxa de armadura. Os padrões de fissuração e os modos de ruptura encontrados foram similares àqueles mostrados pelo $\mathrm{CCP}$, com a conclusão, neste estudo de caso, de que as vigas pré-moldadas, como fabricadas pela empresa, foram superarmadas ao longo do bordo superior. Embora o dimensionamento da viga não tenha sido objeto deste estudo, foi mostrado que o concreto geopolimérico pode substituir plenamente o CCP, em concreto armado, abrindo oportunidade de uso dos mesmos códigos de dimensionamento desenvolvidos para este material tradicional.

Palavras-chave: Geopolímero. Pré-moldado. Concreto armado.

\begin{abstract}
This work presents a comparative study of the mechanical behavior of precast concrete beams (CCP), manufactured by a local company and geopolymer concrete of metakaolin (CCG) and geopolymer concrete with $20 \%$ of fly ash and rice husk ash silicate (CCG-20CV-CCA), as substitutional matrices. The results showed that the geopolymer concretes presented similar behavior to the CCP, in the same class of concrete strength, reinforcement rate and arrangement in the structural element studied. The use of the ashes promoted an increase of the flexural stiffness modulus and the limits of deformation of the geopolymer beams, in particular for the CCG-20CV-CCA under the highest reinforcement rate. The cracking patterns and failure modes found were similar to those shown by CCP, with the conclusion, in this case study, that precast beams, as manufactured by the company were super-reinforced along the top of the beams. Although the dimensioning of the beam has not been the object of this study, it has been shown that the geopolymer concrete can completely replace the $\mathrm{CCP}$ in reinforced concrete, opening up the opportunity to use the same structural design codes developed for this traditional material.
\end{abstract}

Keywords: Geopolymer. Precasting. Reinforced Concrete.

\section{INTRODUÇÃO}

O concreto pré-moldado foi desenvolvido com o propósito de reduzir o custo global das estruturas. Sabe-se que é na parcela relativa às fôrmas e ao cimbramento, normalmente de maior peso no custo do concreto ar- 
mado, que a redução é mais significativa [1,2]. O concreto apresenta tenacidade à fratura baixa em relação ao aço [3]. Os diferentes conceitos de tenacidade e tenacidade à fratura costumam gerar dúvidas. A teoria clássica define tenacidade como a capacidade de um material absorver energia durante a sua deformação até a ruptura, expressa por unidade de volume. Para ZHANG et al. [4] a tenacidade à fratura é definida como a capacidade de um material resistir ao crescimento de uma trinca pré-existente, sendo expressa pela energia absorvida por unidade de extensão da trinca. De acordo com essas definições, a tenacidade engloba a energia necessária para a criação e a propagação de trincas no material, que o levarão à sua ruptura, enquanto a tenacidade à fratura leva em consideração a energia necessária para a propagação de uma dada trinca, sob certo modo de propagação, que o levará à ruptura. Normalmente, para aumentar a tenacidade à fratura de matrizes frágeis, usam-se fibras (curtas ou longas) como elementos de reforço à tração, incumbindo à matriz apenas o combate aos esforços atuantes de compressão. A propensão à formação de trincas e a relativa baixa resistência à tração do concreto simples faz com que se despreze a sua contribuição para a resistência residual do concreto armado fissurado, mas, tal contribuição começa a ser levada em conta, de acordo com alguns estudos feitos por BRANSON [5], GHALI e FAVRE [6] e BISCHOFF [7].

O padrão de fissuração de vigas depende da maneira como ela foi armada, como foi carregada e das propriedades de ambos os materiais (aço e concreto). Na configuração de flexão a 3-pontos o padrão de fissuração da viga se caracteriza pela formação de uma primeira trinca iniciada no bordo inferior tracionado, aproximadamente, alinhada com a linha de ação da carga aplicada no centro do vão da peça, na seção de momento fletor máximo.

Os valores de rigidez à flexão em cada seção de concreto armado variam de acordo com a intensidade das solicitações e da fissuração. A Figura 1 apresenta a distribuição de fissuração em uma viga simplesmente apoiada, indicando que rigidezes maiores são verificadas nas seções onde não existem trincas.

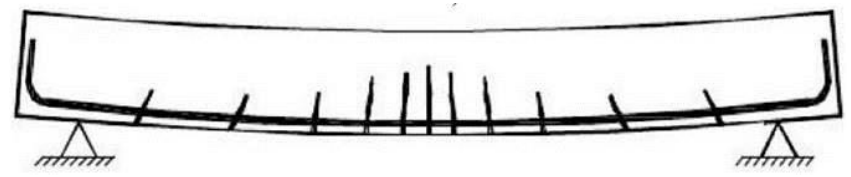

Figura 1: Distribuição de fissuras no elemento fletido [8].

Rigidezes diferentes conduzem a momentos de inércia diferentes para cada seção. BRANSON [5] foi o pioneiro em apresentar uma formulação semi-empírica, considerando o momento de inércia efetivo (equivalente) que é a inércia média interpolada entre o Estádio I e o Estádio II-puro, representando os estágios não-fissurado e fissurado, respectivamente. No Estádio I existe proporcionalidade entre tensão e deformação e a seção de concreto não se apresenta fissurada. A lei de Hooke é empregada, nesse estádio, devido a baixas intensidades de tensão. No Estádio II aparecem as primeiras fissuras, na região mais tracionada do concreto, e considera-se que, na seção de momento fletor máximo, a armadura começa a resistir sozinha aos esforços de tração. Existe uma parcela dos esforços de tração resistida pelo concreto, na seção transversal, porém essa parcela é desprezada. Inicialmente as fissuras se formam e posteriormente se estabilizam ou iniciam o processo de abertura. A Figura 2 mostra o diagrama momento-curvatura de um elemento em concreto fracamente armado, submetido a ensaio de flexão, mostrando a propagação de fissuras em decorrência da intensidade da solicitação [8]. 


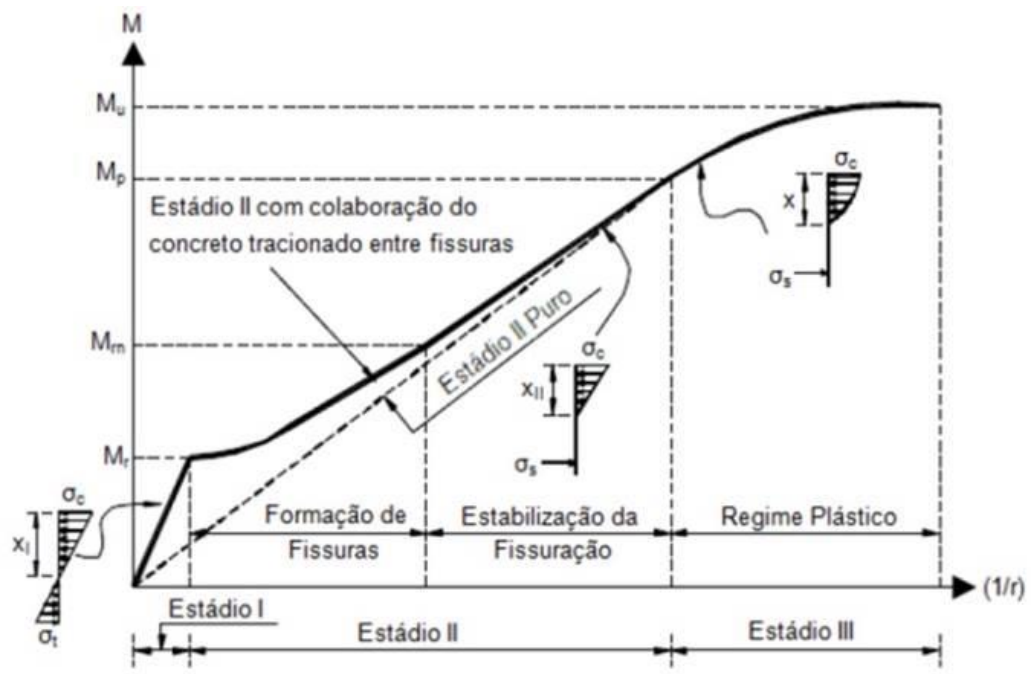

Figura 2: Diagrama momento-curvatura de um elemento estrutural submetido à flexão simples [8].

No Estádio III, considerado fase de colapso, as tensões máximas de compressão do concreto tornam-se plásticas ao longo da seção transversal e a ruína ocorre por esmagamento do concreto na fibra mais comprimida. Observa-se que a região tracionada do concreto é desprezada, quando a viga entra no Estádio II, porém essa consideração é conservadora, já que entre duas fissuras consecutivas existe concreto íntegro, que resiste às solicitações de tração mantidas pela aderência entre o aço e o concreto. Na realidade, essas regiões contribuem com a rigidez do elemento estrutural, conforme apontado por BRANSON [5] e melhor explorado recentemente por BISCHOFF [7] e pela ABNT NBR 6118:2014 [9].

Neste artigo são apresentados os resultados comparativos do comportamento mecânico de vigas prémoldadas de concreto de cimento geopolimérico [10], CCG, e de sua variação de composição pelo emprego de cinza de volante, $\mathrm{CV}$, e de cinza de casca de arroz, CCA, com respeito aos modos de ruptura e padrões de fissuração. $\mathrm{O}$ estudo visou também fazer uma análise comparativa com o cimento Portland e contribuir de forma pioneira para a viabilização técnica e econômica do emprego dos geopolímeros em concreto armado, possibilitando a transferência desta nova tecnologia no âmbito da indústria de pré-fabricados no Brasil. O elemento estrutural adotado foi um produto comercial adquirido pronto, tendo sido reproduzido fac-símile, com as duas diferentes matrizes substitucionais. Portanto, os autores não intervieram no dimensionamento da peça com base nos domínios clássicos de deformação na ruína. Sendo assim, o objetivo do estudo foi apenas caracterizar o comportamento mecânico das peças e realizar a análise comparativa do desempenho entre as matrizes empregadas.

\section{MATERIAIS E MÉTODOS}

A viga pré-moldada de concreto armado de cimento Portland faz parte do kit de elementos estruturais prémoldados para construção de casas pré-fabricadas, de até três pavimentos, oferecido pela empresa Itambi Prémoldados Ltda, localizada no município de Itaboraí-RJ.

As vigas pré-moldadas foram confeccionadas com seção transversal trapezoidal, com pequena variação da espessura da alma (pseudo-T). A largura do topo (mesa) foi de $14 \mathrm{~cm}$ e a largura da base (alma) foi de $10 \mathrm{~cm}$. O comprimento total da viga foi de $235 \mathrm{~cm}$, para operar sobre um vão de $214 \mathrm{~cm}$. Segundo a empresa, o dimensionamento da viga foi realizado como seção subarmada $\left(\varepsilon_{\mathrm{s}} \geq \varepsilon_{\mathrm{yd}}\right)$ conforme a ABNT NBR 6118:2014 [9] em relação à armadura inferior, para que não houvesse ruptura por cisalhamento. Contudo, como a peça precisa ser desmoldada de ponta-cabeça e é transportada e içada nesta disposição, também deve resistir aos esforços de tração na flexão gerados no bordo superior, mas a empresa optou como padrão o uso da mesma taxa geométrica de armadura que aquela usada no bordo inferior da viga. Daí, todas as vigas foram armadas longitudinalmente com duas barras de aço CA 50 de diâmetros 8,0 mm ou 12,5 mm no bordo inferior e duas barras de mesma bitola no bordo superior, configurando taxas geométricas totais de armadura de $0,57 \%$ ou $1,40 \%$, respectivamente. Os detalhes da viga são mostrados na Figura 3. 

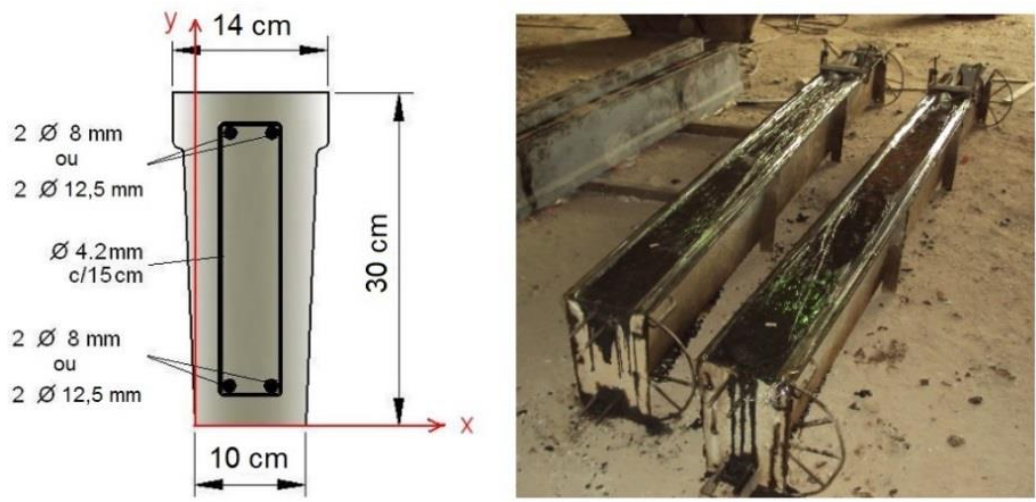

Figura 3: Detalhamento da seção transversal da viga pré-moldada e respectivas fôrmas para moldagem. Notar na foto as vigas dispostas de ponta-cabeça após a desforma.

Como se trata de elemento pré-moldado, também foram consideradas as prescrições da ABNT NBR 9062:2006 [14], estabelecendo como uma das variáveis estudadas, a classe resistência à compressão do concreto. As demais variáveis, assim como as matrizes e proporções em massa entre os constituintes do concreto, para ambas as classes de resistência e as taxas geométricas de armadura empregadas são mostradas na Tabela 1

A armadura transversal foi composta por estribos de aço CA 60 com 4,2 mm de diâmetro, dispostos verticalmente e espaçados em $15 \mathrm{~cm}$. Todas as barras de aço foram de fabricação da Gerdau S.A. As características mecânicas dos aços da armadura longitudinal e dos estribos são mostradas na Tabela 2.

Tabela 1: Descrição das variáveis estudadas.

\begin{tabular}{|c|c|c|c|}
\hline MATRIZ & $\begin{array}{c}\text { CLASSE } \\
\text { (MPa) }\end{array}$ & TRAÇO (c:a:p:x) & $\begin{array}{c}\text { BITOLA, } \boldsymbol{\varnothing}(\mathbf{m m}) ; \text { TX. GEOM. } \\
\text { DE ARMADURA, } \boldsymbol{\rho}(\%)\end{array}$ \\
\cline { 1 - 4 } CCP & 25 & $1: 2,00: 1,57: 0,46$ & 8,$0 ; 0,57$ \\
\cline { 1 - 4 } CCG & 40 & $1: 1,26: 0,99: 0,36$ & 12,$5 ; 1,40$ \\
\cline { 1 - 1 } CCG-20CV-CCA & &
\end{tabular}

* (aglomerante seco : areia : brita zero : água), em massa.

O cimento Portland empregado na confecção do concreto de referência foi o CPIIF-32, fabricado pela Lafarge/Mauá S.A. e adquirido no mercado local. A areia utilizada foi natural de rio, lavada, com módulo de finura 2,66 e $\mathrm{D}_{\text {máx }}$ de 2,34 mm. A brita foi de origem gnáissica, com módulo de finura 5,73 e $\mathrm{D}_{\text {máx }}$ de $9,5 \mathrm{~mm}$. O cimento geopolimérico empregado na confecção dos concretos, foi fornecido pela Wincret Designer Concrete Products Ltda, com sede em São Paulo/SP, chamado comercialmente de Cimento Geo-Pol ${ }^{\circledR}$, com relação $\mathrm{SiO}_{2} / \mathrm{Al}_{2} \mathrm{O}_{3}$ igual a 5,35 e $\left(\mathrm{Na}_{2} \mathrm{O}+\mathrm{K}_{2} \mathrm{O}\right) / \mathrm{SiO}_{2}$ igual a 0,209 . Uma modificação especial também foi estudada, com $20 \%$ de cinza volante e um ativador alcalino: silicato de sódio alternativo, feito a partir da cinza da casca de arroz (CCG-20CV-CCA), com base nos trabalhos de HABEEB e MAHMUD [11], BIGNO [12] e VARGAS [13].

Tabela 2: Características mecânicas dos aços.

\begin{tabular}{l|c|c|c}
\hline \multicolumn{1}{c|}{ DIÂMETRO $(\mathbf{m m})$} & $\mathbf{4 , 2}$ & $\mathbf{8 , 0}$ & $\mathbf{1 2 , 5}$ \\
\hline Tensão de escoamento, $f_{\mathrm{yk}}(\mathrm{MPa})$ & 804 & 578 & 579 \\
\hline Módulo de elasticidade, $\mathrm{E}_{\mathrm{s}}(\mathrm{GPa})$ & 216 & 215 & 214 \\
\hline Def. no escoamento, $\varepsilon_{\mathrm{yk}}(\%)$ & 0,372 & 0,283 & 0,271 \\
\hline Def. na ruptura, $\varepsilon_{\mathrm{r}}(\%)$ & 16,7 & 14,4 & 14,8 \\
\hline Área final, $\mathrm{A}_{\mathrm{f}}\left(\mathrm{mm}^{2}\right)$ & 5,31 & 21,24 & 33,94 \\
\hline Estricção $(\%)$ & 51,03 & 75,71 & 72,34 \\
\hline
\end{tabular}

Para o cobrimento das armaduras, foi adotada a espessura de $2,5 \mathrm{~cm}$, considerando exposição a ambientes não-agressivos, Classe I, da ABNT NBR 6118:2014 [9]. A Figura 4 mostra a configuração de ensaio das vigas, sob flexão a 3-pontos. 


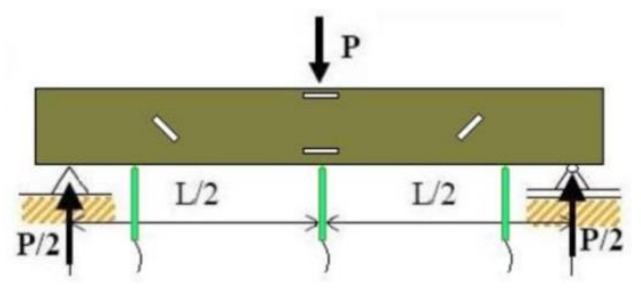

(a)

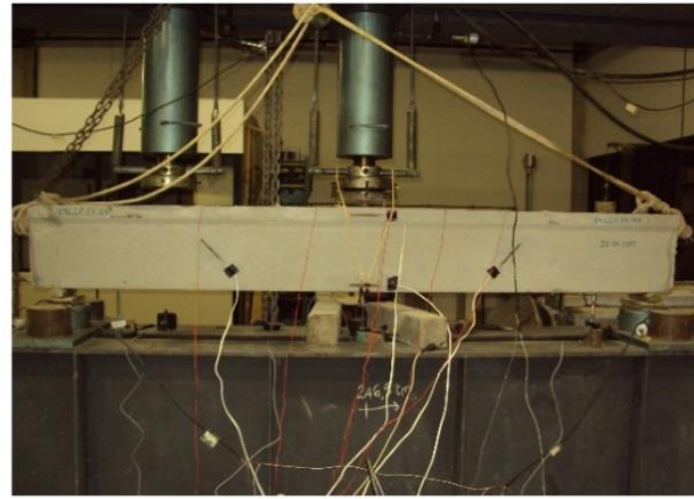

(b)

Figura 4 (a, b): Configuração do ensaio de flexão a 3-pontos das vigas pré-moldadas de concreto armado.

Todas as vigas pré-moldadas de concreto armado também foram ensaiadas sob flexão a 3-pontos, com carga concentrada no meio do vão, sob taxa de carregamento monotônico de $0,5 \mathrm{kN} \pm 0,1 \mathrm{kN} / \mathrm{s}$. Seus valores, assim como os das reações de apoio, foram obtidos individualmente a partir de transdutores de pressão, marca Druken, com capacidade para $500 \mathrm{kN}$ e sensibilidade de $1 \mathrm{kN}$. Além da carga aplicada, também foram monitoradas as extensões instantâneas das trincas nas faces laterais das vigas e as deflexões instantâneas no meio do vão. A extensão instantânea da trinca foi determinada por meio de acompanhamento de sua ponta visível, localizada por inspeção ótica com câmera digital dotada de lente 18-55 mm com close-up +10 (macro), marca Sony. A sua trajetória foi assinalada com marcador permanente de ponta fina e quantificada por hodômetro cartográfico digital, marca Scale Master, a cada interrupção de incremento de carga de $5 \mathrm{kN}$. As flechas no meio do vão foram obtidas usando-se transdutores resistivos de deslocamento linear, marca Gefran, com curso elétrico de $100 \mathrm{~mm}$ e precisão de $0,01 \mathrm{~mm}$. As deformações no concreto e nas armaduras também foram registradas, mas o presente trabalho não apresenta a análise e a discussão destes resultados.

$\mathrm{O}$ módulo de elasticidade secante e a resistência à compressão foram determinados conforme as prescrições da ABNT NBR 8522:2003, item 3.5 [15] e ABNT NBR 5739:1994 [16], respectivamente. Todos os sensores elétricos foram lidos por meio do sistema de aquisição de dados modelo cDAQ-9217, da National Instruments, assistido pelo programa LabView 8.6.

\section{RESULTADOS E DISCUSSÃO}

Os resultados dos ensaios de resistência à compressão, $\mathrm{f}_{\mathrm{c}}$, resistência à tração por compressão diametral, $\mathrm{f}_{\mathrm{ct}, \mathrm{sp}}$, módulo de elasticidade secante, $\mathrm{E}_{\mathrm{cs}}$, razão de Poisson, v, e abatimento do tronco de cone (slump) para todos os tipos de concreto estudados, aos 28 dias de idade, são mostrados na Tabela 3. Constata-se, portanto, o desempenho semelhante ou ligeiramente superior dos concretos geopoliméricos, em relação ao Portland, nas duas classes de resistência, com destaque para a CCG-20CV-CCA_40.

Tabela 3: Valores médios das propriedades mecânicas dos concretos estudados.

\begin{tabular}{c|c|c|c|c|c|c}
\hline MATRIZ & $\begin{array}{c}\text { CLASSE } \\
(\mathbf{M P a})\end{array}$ & $\mathbf{f}_{\mathbf{c}}(\mathbf{M P a})$ & $\begin{array}{c}\mathbf{f}_{\mathrm{ct}, \mathbf{s p}} \\
(\mathbf{M P a})\end{array}$ & $\mathbf{E}_{\mathrm{cs}}(\mathbf{G P a})$ & $\mathbf{U}$ & $\begin{array}{c}\text { SLUMP } \\
(\mathbf{m m})\end{array}$ \\
\hline \multirow{3}{*}{$\mathrm{CCP}$} & 25 & $25,59 \pm 1,87$ & $2,33 \pm 0,17$ & $25,50 \pm 0,94$ & $0,25 \pm 0,01$ & 60 \\
\cline { 2 - 7 } & 40 & $50,48 \pm 2,48$ & $4,08 \pm 0,38$ & $28,06 \pm 0,83$ & $0,22 \pm 0,02$ & 65 \\
\hline \multirow{3}{*}{ CCG } & 25 & $26,18 \pm 1,32$ & $2,38 \pm 0,13$ & $23,00 \pm 0,42$ & $0,26 \pm 0,03$ & 80 \\
\cline { 2 - 7 } & 40 & $51,61 \pm 4,21$ & $4,24 \pm 0,29$ & $29,48 \pm 0,25$ & $0,24 \pm 0,02$ & 88 \\
\hline \multirow{2}{*}{ CCG- } & 25 & $32,02 \pm 1,06$ & $3,04 \pm 0,30$ & $24,16 \pm 2,41$ & $0,23 \pm 0,02$ & 74 \\
\cline { 2 - 7 } 20CV-CCA & 40 & $53,50 \pm 2,43$ & $4,84 \pm 0,54$ & $27,76 \pm 3,02$ & $0,24 \pm 0,01$ & 80 \\
\hline
\end{tabular}

O monitoramento das trincas foi feito com objetivo de relacionar a carga aplicada na viga com o somatório de todas as extensões individuais das trincas que surgiram na viga até o seu colapso, que foi 
assumido quando o strain gage situado a 2,5 $\mathrm{cm}$ do bordo superior da viga parou de emitir sinal elétrico por ter sido danificado pelas trincas.

A princípio foi considerado que a região do bordo superior havia sido fragmentada pelo esmagamento do concreto em compressão. Contudo, após a análise da ruptura, foi confirmado que houve excesso de reforço no bordo superior da viga, o que evitou que o concreto fosse solicitado a ponto de atingir o seu limite de resistência à compressão. Portanto, o bordo superior foi parcialmente comprimido, descomprimido e posteriormente tracionado com o decorrer do ensaio, pelo deslocamento da linha neutra em direção àquele bordo, gradativamente. A carga aplicada na viga foi sempre crescente até a interrupção do ensaio quando da fragmentação superficial do bordo superior da viga, que, mais tarde, foi constatado que ocorreu por efeito de punção provocado pelo cutelo. A Figura 5 mostra os padrões de fissuração para as vigas da classe $25 \mathrm{MPa}$, bitola de $8,0 \mathrm{~mm}$.

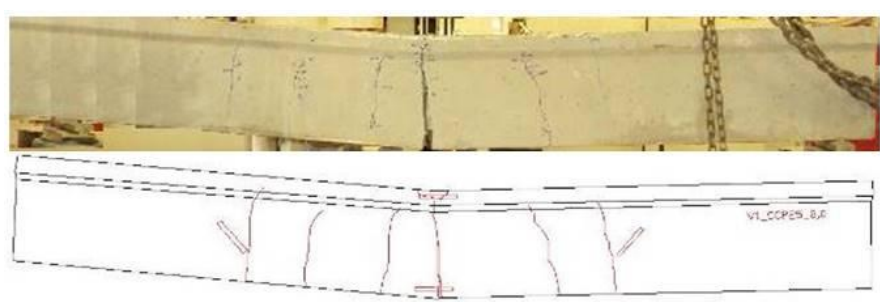

(a) $C C P \_25 \_8,0$.

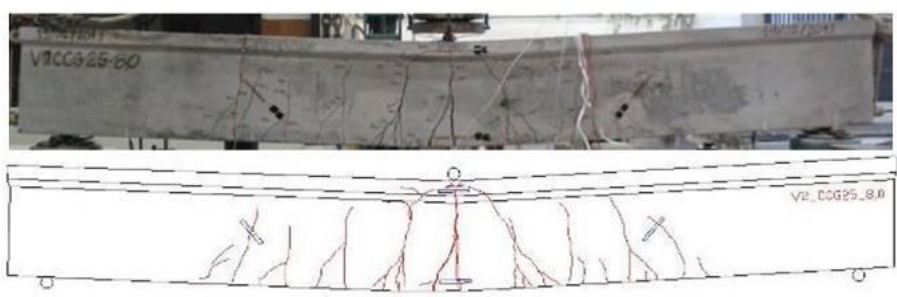

(b) $C C G \_25 \_8,0$.

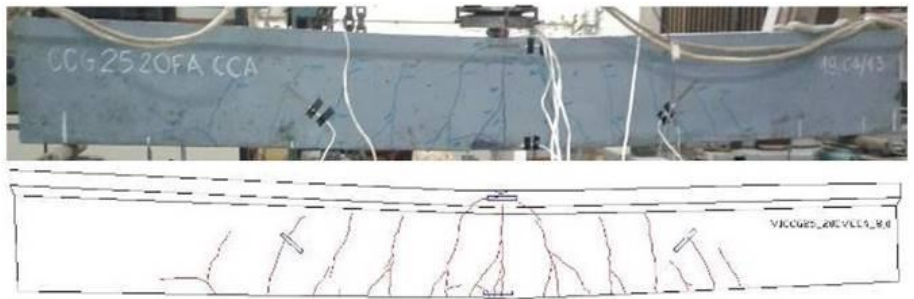

(c) CCG-20CV-CCA_25_8,0.

Figura 5: Padrões de fissuração para as vigas da classe $25 \mathrm{MPa}$ e armadura de $\phi 8,0 \mathrm{~mm}$.

A Figura 6a-c mostra os padrões de fissuração para as vigas da classe 25 e bitola de $12,5 \mathrm{~mm}$. O padrão de fissuras de todas as vigas foi considerado similar, com ligeiro destaque para a CCG_25_12,5. Este fato evidencia que a taxa de armadura tem maior influência no comportamento global da viga do que o tipo de concreto, já que a classe de resistência foi a mesma. A Figura 7 mostra o somatório das extensões de todas as trincas aparentes na face lateral dessas vigas $(\Sigma a)$, em função da carga aplicada, P. A progressão individual de cada trinca aparente (macroscópica) na superfície do concreto foi registrada de modo a permitir que o somatório das extensões fosse tomado como dado comparativo entre as vigas, sob o mesmo valor de carga aplicada. Desta forma, partiu-se do pressuposto que, para uma dada carga, inferior à carga de ruptura, quanto maior o número e/ou a extensão total de trincas, maior a capacidade de distribuição das deformações permanentes e, portanto, maior a tenacidade do elemento estrutural. 


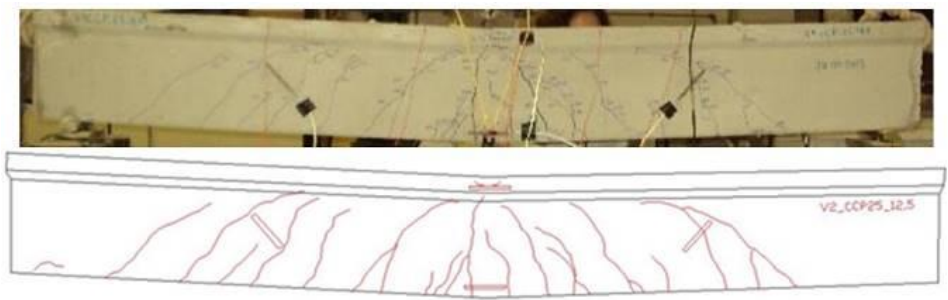

(a) CCP_25_12,5.
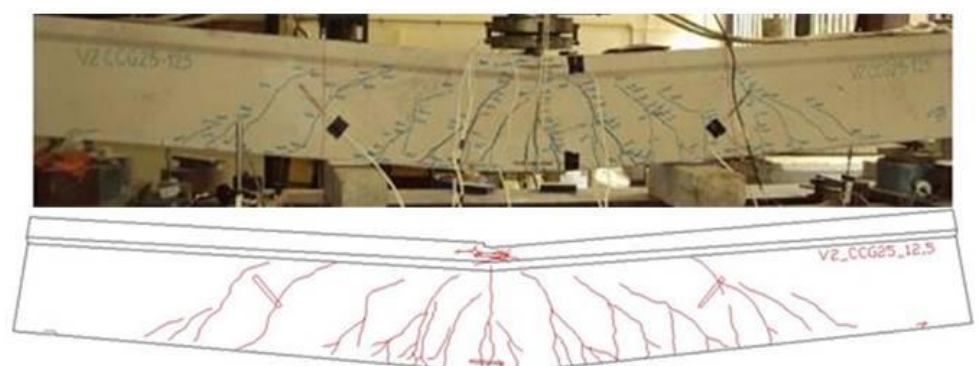

(b) $C$ CG_25_12,5.

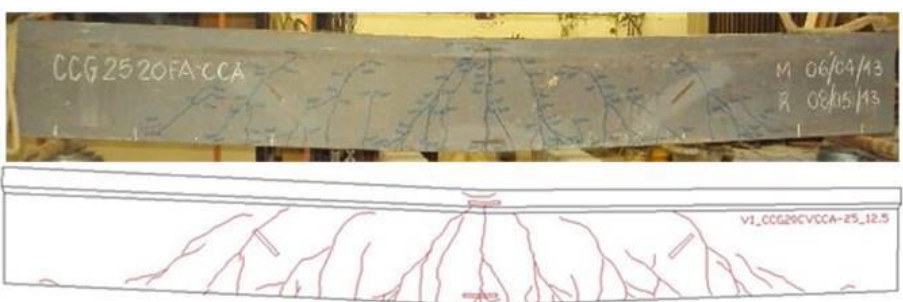

(c) CCG-20CV-CCA_25_12,5.

Figura 6: Padrões de fissuração para as vigas da classe $25 \mathrm{MPa}$ e armadura de $\phi 12,5 \mathrm{~mm}$.

Observando a evolução das trincas em função da carga aplicada (Figura 7), notou-se que, até cerca de $50 \%$ da carga máxima, todas as vigas da classe 25 e bitola $12,5 \mathrm{~mm}$ apresentaram valores muito próximos de taxa de extensão total de trincas. A partir desse nível de carga, os comportamentos se diferiram, revelando novamente a menor tenacidade para a CCP_25_12,5. O conceito de tenacidade já foi apresentado na introdução deste artigo [4].

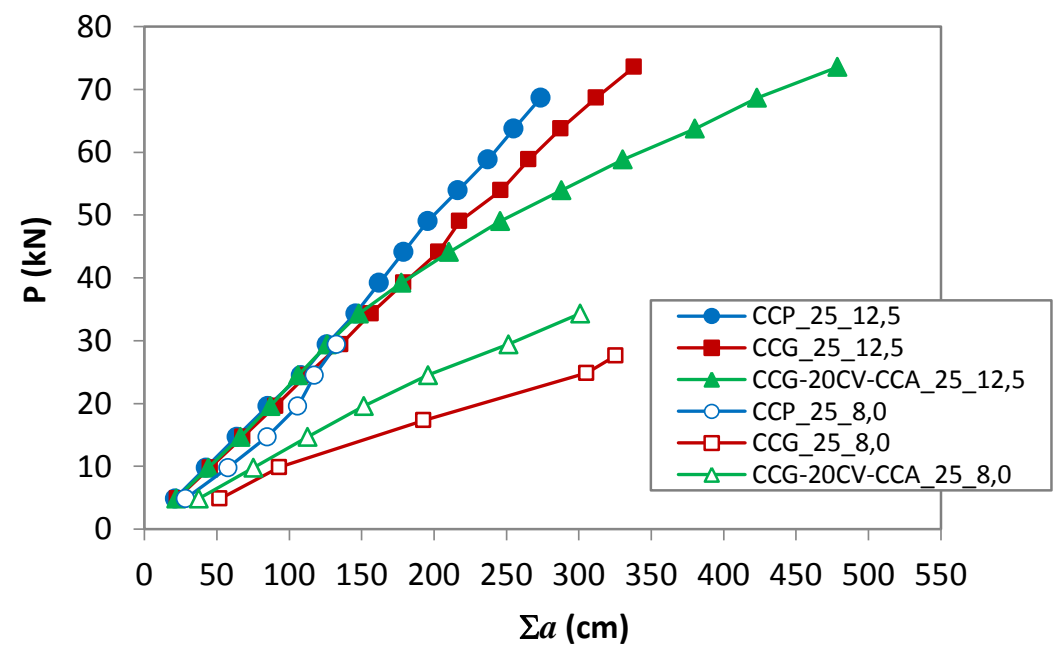

Figura 7: Extensão total de trincas para as vigas de concretos Portland e Geopoliméricos de $25 \mathrm{MPa}$. 
A comparação entre as vigas geopoliméricas mostrou que, dependendo da taxa de armadura, houve alternância de destaque. Para a taxa geométrica de armadura de 0,57\% (bitola de 8,0 mm), o padrão mais fissurado, com maior extensão total de trincas e flecha máxima no meio do vão foi apresentado pela CCG_25_8,0 e o menos fissurado pela CCP_25_8,0. Para a classe 25 e taxa geométrica de armadura de $1,40 \%$ (bitola de $12,5 \mathrm{~mm}$ ), a extensão total de trincas e o padrão das vigas geopoliméricas foi muito similar entre si e com aqueles do CCP_25_12,5, até cerca de $30 \mathrm{kN}$. A partir daí e até $45 \mathrm{kN}$, as vigas geopoliméricas apresentaram maior extensão total de trincas que a CCP_25_12,5, mas ainda equivalente entre ambas. Acima de 45 kN, a CCG-20CV-CCA_25_12,5 foi a que mais propagou trincas e se acomodou aos esforços.

Para a classe de $40 \mathrm{MPa}$, dois grupos bem distintos aparecem em função da taxa de armadura e da carga máxima alcançada (Figura 8).

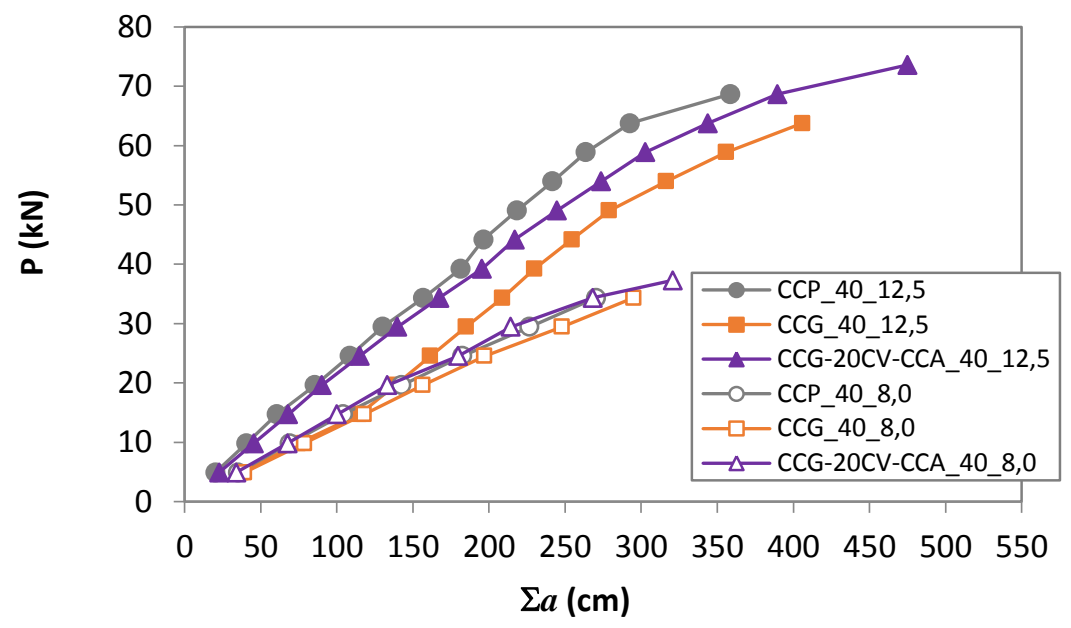

Figura 8: Extensão total de trincas para as vigas de concretos Portland e Geopoliméricos de $40 \mathrm{MPa}$.

Contudo, a relação carga-extensão total de trincas mostra que a CCG_40_12,5 apresentou rigidez equivalente a das vigas de bitola $8,0 \mathrm{~mm}$, pelo menos até atingir o momento resistente da seção homogeneizada [7], de formação da $1^{\text {a }}$ trinca, em aproximadamente $15 \mathrm{kN}$. A partir daí, se destaca, apresentando comportamento similar, porém um pouco mais dúctil que das demais vigas de bitola 12,5 $\mathrm{mm}$. Analisando o comportamento global das vigas da classe $40 \mathrm{MPa}$, destacam-se a CCG-20CV-CCA_40_12,5 como a que desenvolveu ductilidade intermediária, revelando que as cinzas conferem um caráter de enrijecimento ao geopolímero, exigindo mais energia para exibir a mesma fissuração total. Os padrões de fissuração para as vigas da Classe 40 são mostrados nas Figuras 9 e 10, para as armaduras de bitola 8,0 e 12,5 mm, respectivamente.

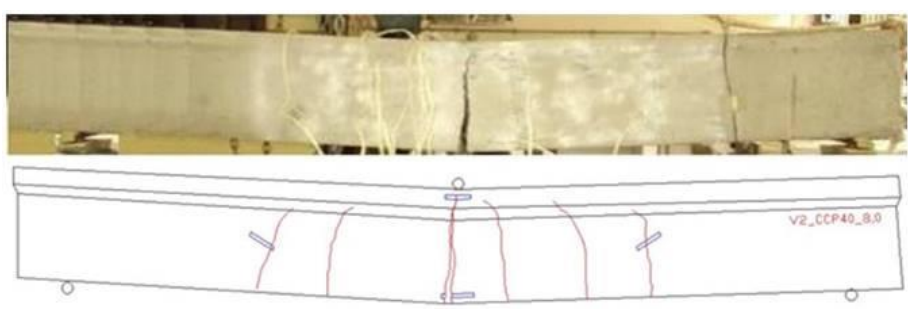

(a) CCP_40_8,0.

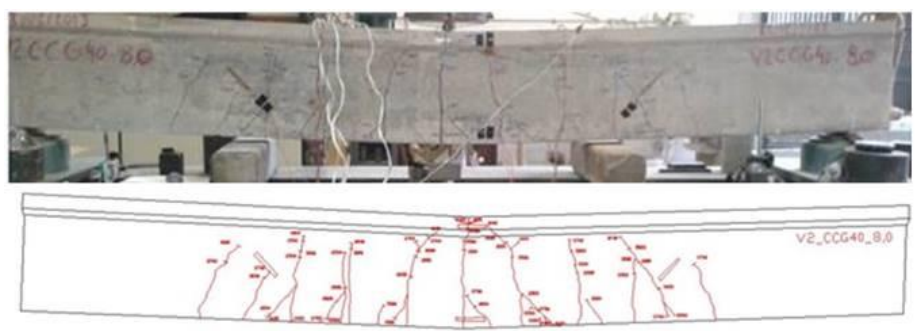

(b) $\mathrm{CCG}$ _40_8,0. 


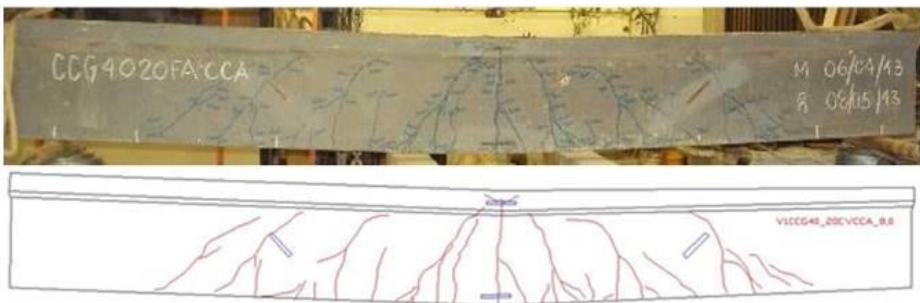

(c) CCG-20CV-CCA_40_8,0.

Figura 9: Padrões de fissuração para as vigas da classe $40 \mathrm{MPa}$ e armadura de $\phi 8,0 \mathrm{~mm}$.

Para a bitola de $12,5 \mathrm{~mm}$ os padrões de fissuração das vigas da classe 40 foram similares aos apresentados pelas vigas da classe 25. O padrão menos fissurado continuou sendo gerado na CCP_40_12,5 e as vigas geopoliméricas com padrões similares e bem mais fissurados (Figura 10a). O relacionamento P- $\Sigma a$ também mostrou destaque para a maior rigidez da CCP_40_12,5, seguida da CCG-20CV-CCA_40_12,5 e da CCG_40_12,5, respectivamente.
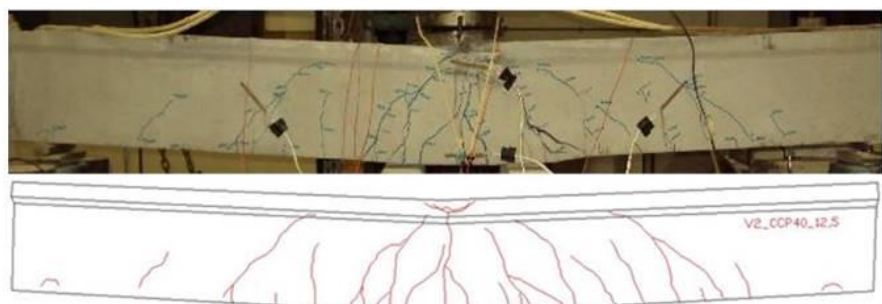

a) CCP_40_12,5.
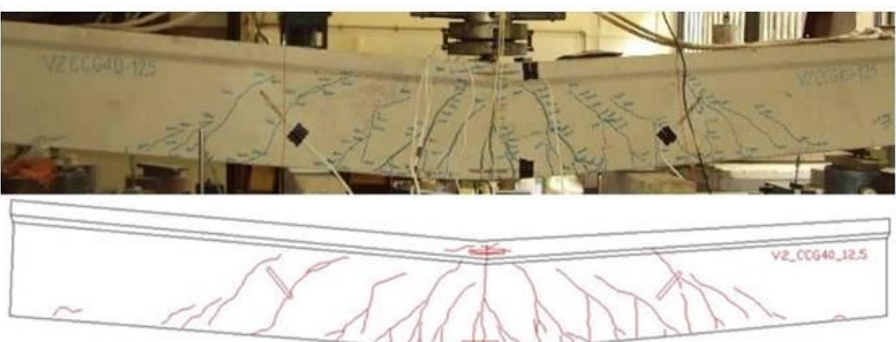

(b) CCG_40_12,5.

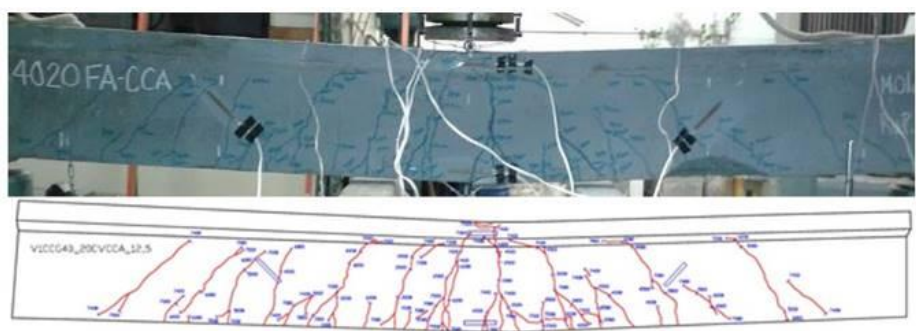

(c) CCG-20CV-CCA_40_12,5.

Figura 10: Padrões de fissuração para as vigas da classe $40 \mathrm{MPa}$ e armadura de $\phi 12,5 \mathrm{~mm}$.

As vigas com armadura de 12,5 mm tiveram, na ruptura, maiores quantidades de trincas e com inclinações um pouco mais acentuadas, quando comparadas com as vigas com armadura de 8,0 mm. O espaçamento entre as trincas diminuiu à medida que se aumentou a taxa geométrica de armadura. Tal como esperado, todas as vigas romperam por flexão, com o escoamento da armadura inferior (sob tração) e colapso do concreto superior também em tração, seguido do esmagamento superficial do concreto por punção do cutelo no bordo superior da viga. Não houve, portanto, ruptura do concreto por compressão no bordo superior da viga, porque, como suposto, a armadura superior, de mesma bitola e taxa geométrica de armadura que no bordo inferior, superarmou a viga, causando ruptura por deformação excessiva, supostamente entre o Domí- 
nio II (flexão simples sem ruptura do concreto em compressão) e o Domínio I (tração não uniforme no concreto superior).

A análise do padrão de fissuração das vigas pré-moldadas de concreto armado revelou que houve o aparecimento de um maior número de fissuras nas vigas de concreto geopolimérico, assim como de maior extensão total de propagação, indicando maior tenacidade [18]. Este comportamento corrobora com os resultados de tenacidade à fratura obtidos em estudos complementares realizados por PIRES [19].

Os resultados dos ensaios de flexão, quanto à relação carga, $\mathrm{P}$ x flecha no meio do vão, $\delta$ são mostrados nas Figuras 11a e 11b, agrupados por matriz, classe de resistência e bitola da armadura, para todas as vigas pré-moldadas de concreto Portland e geopoliméricos, das classes $25 \mathrm{MPa}$ e $40 \mathrm{MPa}$, respectivamente. Para melhor comparação com o exemplo mostrado na Figura 2, os resultados foram convertidos na relação momento, M x curvatura, (1/r), e mostrados nas Figuras 13 e 14.
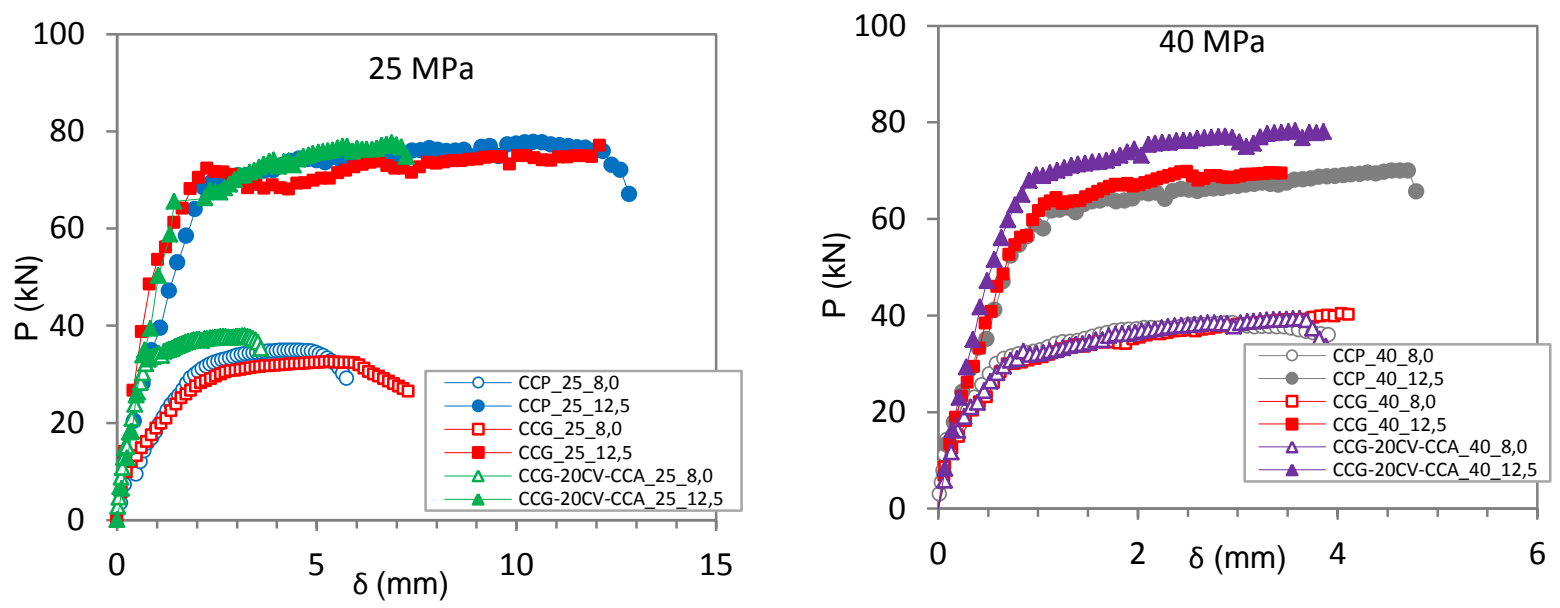

Figura 11: Curvas carga x flecha de vigas de concreto armado da classe de resistência (a) de $25 \mathrm{MPa}$; (b) de $40 \mathrm{MPa}$, para as diferentes taxas de armadura e matrizes de concreto.

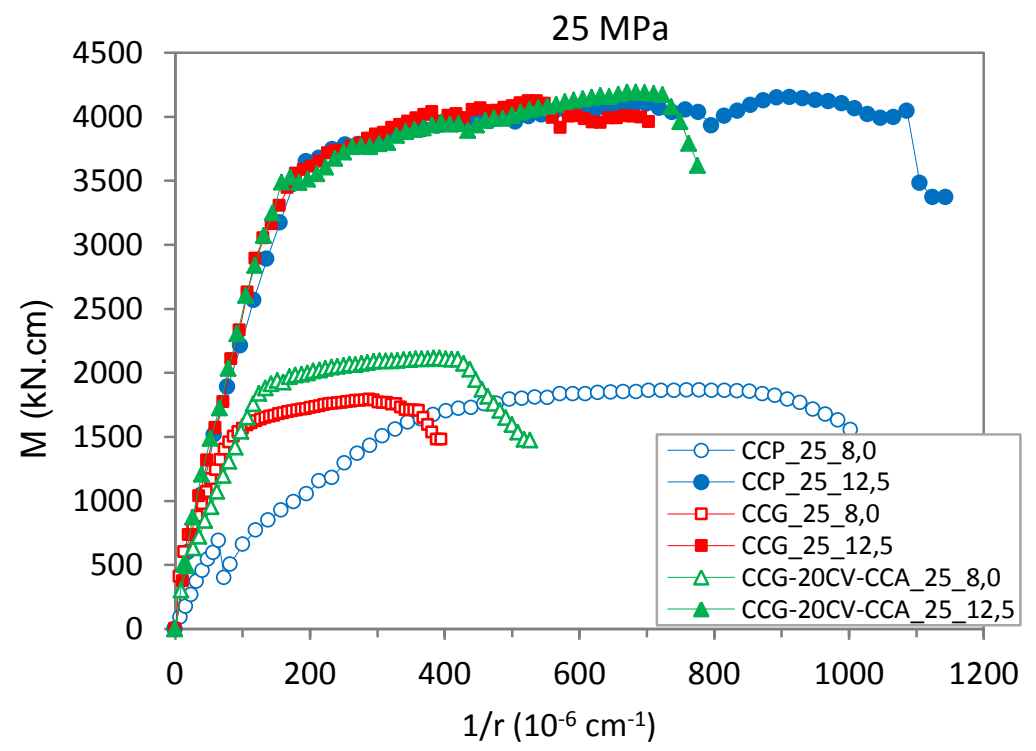

Figura 12: Curvas momento x curvatura das vigas de concreto armado com classe de resistência de $25 \mathrm{MPa}$, para as diferentes taxas de armadura e matrizes de concreto. 
Como esperado, as vigas com armadura de bitola 8,0 $\mathrm{mm}$ apresentaram maiores flechas e curvaturas que aquelas com armadura de bitola 12,5 mm. Quanto à classe de resistência do concreto, foi observado que houve influência sobre a rigidez inicial das vigas com armadura de bitola 8,0 $\mathrm{mm}$, ao passo que naquelas de bitola de 12,5 mm o comportamento foi idêntico até o fim do Estádio II (início escoamento da armadura inferior), em Ma $\approx 3200 \mathrm{kN}$.cm. Também foi clara a distinção de comportamentos, em função da bitola, para todo o regime de solicitação. A Tabela 4 mostra uma compilação dos resultados de flexão, levando-se em conta as propriedades na fase intermediária do carregamento, até o início do escoamento da armadura inferior.

Foi observado que, nas vigas com menor taxa de armadura, o momento de plastificação girou em torno de $1800 \mathrm{kN} . \mathrm{cm}$ e para a maior taxa geométrica de armadura, girou em torno de $3500 \mathrm{kN} . \mathrm{cm}$, quase $100 \%$ a mais de capacidade de carga, como era presumido.

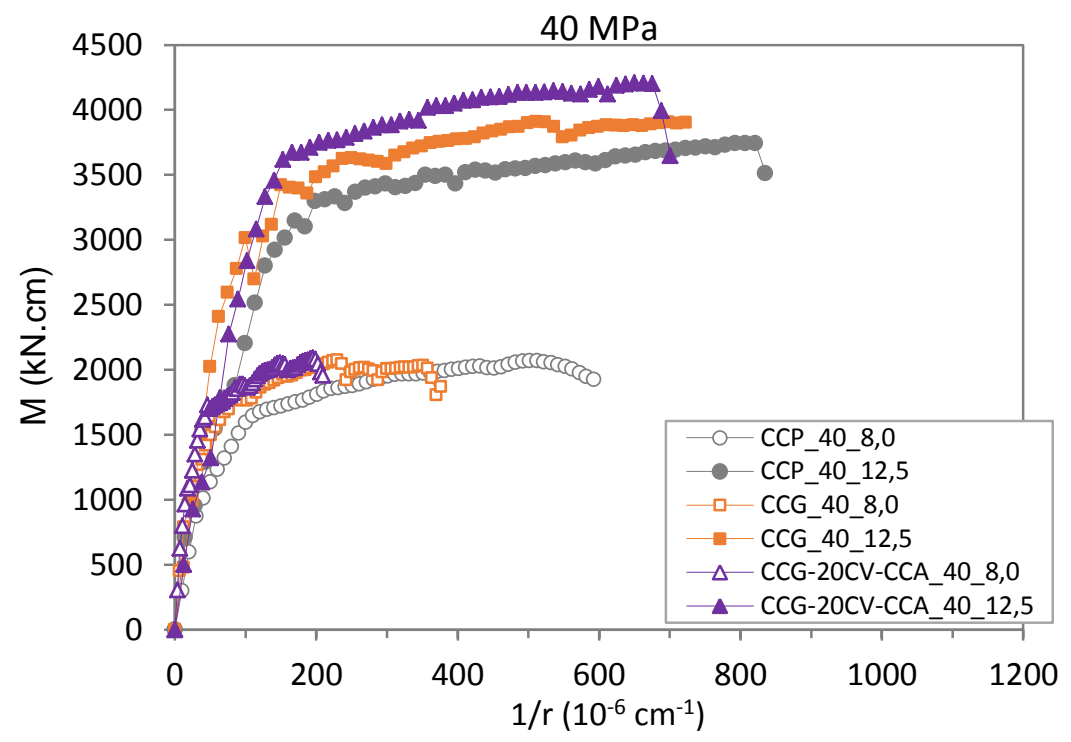

Figura 13: Curvas momento $x$ curvatura das vigas de concreto armado com classe de resistência de $40 \mathrm{MPa}$, para as diferentes taxas de armadura e matrizes de concreto.

Numa análise primária, pode-se afirmar que houve pouca influência do tipo de matriz e da classe de resistência do concreto sobre esse resultado. Contudo, numa observação mais criteriosa, pode ser percebido o melhor desempenho das vigas de matriz geopolimérica em relação às de cimento Portland, principalmente das CCG-20CV-CCA, onde aquelas de classe 40 e bitola de $12,5 \mathrm{~mm}$ se sobrepõem a todas as demais.

Tabela 4: Valores médios de alguns parâmetros determinados nas vigas na fase final do Estádio-II.

\begin{tabular}{|c|c|c|c|c|c|c|c|}
\hline MATRIZ & $\begin{array}{l}\text { CLASSE } \\
\text { (MPa) }\end{array}$ & $\begin{array}{l}\text { BITOLA, } \\
\varnothing(\mathrm{mm})\end{array}$ & $\begin{array}{l}\text { MÓDULO DE } \\
\text { RIGIDEZ A FLE- } \\
\text { XÃO, } E_{\mathrm{cs} . \mathrm{I}_{\mathrm{I}}} \\
\left(\times 10^{4} \mathrm{kN} . \mathrm{cm}^{2}\right)\end{array}$ & $\begin{array}{c}\text { CARGA DE } \\
\text { PLASTIFICAÇÃO, } \\
P_{Y}(k N)\end{array}$ & $\begin{array}{c}\text { MOMENTO DE } \\
\text { PLASTIFICAÇÃO, } \\
\mathbf{M}_{\mathrm{Y}}(\mathrm{kN} . \mathrm{cm})\end{array}$ & $\begin{array}{l}\text { FLECHA, NO } \\
\text { MEIO DO VÃO, } \\
\delta_{\mathrm{Y}}(\mathrm{cm})\end{array}$ & $\begin{array}{c}\text { CURVATURA, } \\
(1 / \mathrm{r})_{\mathrm{r}} \\
\left(\times 10^{-6} \cdot \mathrm{cm}^{-1}\right)\end{array}$ \\
\hline \multirow{4}{*}{$\mathrm{CCP}$} & \multirow{2}{*}{25} & 8,0 & 6995,05 & 30,68 & 1641,63 & 2,084 & 364,79 \\
\hline & & 12,5 & 7715,22 & 68,28 & 3653,23 & 1,114 & 194,58 \\
\hline & \multirow{2}{*}{40} & 8,0 & 7659,28 & 31,33 & 1676,21 & 0,690 & 120,53 \\
\hline & & 12,5 & 8350,28 & 61,85 & 3309,17 & 1,218 & 212,71 \\
\hline \multirow{4}{*}{ CCG } & \multirow{2}{*}{25} & 8,0 & 6364,87 & 30,10 & 1610,39 & 0,652 & 113,89 \\
\hline & & 12,5 & 7094,53 & 67,52 & 3612,58 & 1,162 & 202,96 \\
\hline & \multirow{2}{*}{40} & 8,0 & 8017,28 & 32,98 & 1764,25 & 0,511 & 89,26 \\
\hline & & 12,5 & 8703,06 & 63,97 & 3422,40 & 0,857 & 149,70 \\
\hline \multirow{2}{*}{$\begin{array}{c}\text { CCG- } \\
\text { 20CV-CCA }\end{array}$} & \multirow{2}{*}{25} & 8,0 & 6656,01 & 36,27 & 1940,24 & 0,870 & 151,97 \\
\hline & & 12,5 & 7381,28 & 65,26 & 3491,30 & 0,905 & 158,08 \\
\hline
\end{tabular}




\begin{tabular}{l|c|c|c|c|c|c|c}
\hline \multirow{2}{*}{40} & 8,0 & 7586,59 & 32,58 & 1743,10 & 0,345 & 60,27 \\
\cline { 3 - 7 } & & 12,5 & 8278,87 & 68,62 & 3671,36 & 1,023 & 178,69 \\
\hline
\end{tabular}

No outro extremo, apresentando pior desempenho, aparecem as vigas de CCP_25_8,0 com menores rigidez e capacidade de carga. Com base nesses resultados, o emprego de modelos constitutivos de nãolinearidade física (NLF) propostos para os CCP pode ser considerado como um meio eficaz de análise comparativa com os geopolímeros, já que se trata da mesma base de memória de cálculo que se encontra nas normas brasileiras e nos códigos internacionais. A modelagem numérica por elementos finitos é também uma poderosa ferramenta para análise da fissuração em vigas, submetidas a quaisquer regimes de carregamento [19].

\section{CONCLUSÕES}

Os resultados experimentais mostraram que, para o comportamento à flexão, as vigas pré-moldadas de concreto geopolimérico apresentaram capacidade de carga elevada, maior habilidade de deformação e formação de trincas finas e mais numerosas no meio do vão, em comparação com vigas pré-moldadas de concreto de cimento Portland. Todas as propriedades avaliadas neste artigo indicam que, tanto o CCG quanto os híbridos gerados pelo emprego de CV e CCA, são plenamente capazes de desempenhar a função de aglomerante em concreto armado, tão bem ou em certos casos, melhor que o cimento Portland, abrindo oportunidade para o emprego dos mesmos modelos constitutivos desenvolvidos para o concreto armado convencional, para o dimensionamento de estruturas.

\section{AGRADECIMENTOS}

Os autores agradecem a CAPES e a FAPERJ, pelo aporte financeiro, ao Laboratório de Materiais Conjugados do Instituto Militar de Engenharia, IME, pelo empréstimo de instrumentação, as empresas Geopolitec e Wincret, pela cessão de material e a Itambi Pré-moldados pela total disponibilização de suas instalações.

\section{BIBLIOGRAFIA}

[1] AMERICAN CONCRETE INSTITUTE. ACI 347R-14: Guide to formwork for concrete. 32p, 2014.

[2] EL DEBS, M. K. Concreto pré-moldado: fundamentos e aplicações, 1 ed, São Carlos, S.P., EESC-USP, 2000.

[3] BAZANT, Z. P., KAZEMI, M. T. "Determination of fracture energy, process zone length and brittleness number from size effect, with application to rock and concrete", International Journal of Fracture, v. 44, n. 2 , pp. 111-131, 1990.

[4] ZHANG, S., SUN, D., FU, Y., et al. "Toughness measurement of thin films: a critical review”. Surface and Coatings Technology, v.198, pp.74 - 84, Aug. 2005.

[5] BRANSON, D. E. Instantaneous and time-dependent deflections of simple and continuous reinforced concrete beams, 1 ed., Auburrn,. HPR Publication, Alabama Highway Departament, U. S. Bureau of Publis Roads, n. 7, part 1, pp. 1-78, Aug, 1965.

[6] GHALI, A., FAVRE, R. Concrete structures: stresses and deformations, 2 ed., London, E \& FN Spon, Chapman and Hall, 1994.

[7] BISCHOFF, P. H. "Rational model for calculating deflection of reinforced concrete beams and slabs", Canadian Journal of Civil Engineering, v. 34, n. 8, pp. 992-1002, 2007.

[8] GUARDA, M. C. C. Cálculo de deslocamentos em pavimentos de edifícios de concreto armado, Tese de D.Sc., Escola de Engenharia de São Carlos/USP. São Carlos, SP, Brasil, 2005.

[9] ASSOCIAÇÃO BRASILEIRA DE NORMAS TÉCNICAS. NBR 6118: Projeto de estruturas de concreto - procedimento. Rio de Janeiro, 2014. 238 p.

[10] SILVA, F. J., OLIVEIRA, M. C., MACHADO, M. V. S., et al., "Cimentos geopoliméricos”, Revista Matéria (UFRJ), v. 7, pp. 14-28, 2002.

[11] HABEEB, G. A., MAHMUD, H. B. "Study on properties of rice husk ash and its use as cement replacement material", Materials Research, v 13, n 2, pp 185-190, 2010.

[12] BIGNO, I. C. Geopolímeros à base de resíduos agrícolas e agroindustriais. Tese de D.Sc, IME, Rio de 
Janeiro, RJ, Brasil, 2008.

[13] VARGAS, A. S. Cinzas volantes álcali-ativadas para obtenção de aglomerantes especiais, Tese de D.Sc., UFRGS, Porto Alegre, RS, Brasil, 2006.

[14] ASSOCIAÇÃO BRASILEIRA DE NORMAS TÉCNICAS. NBR 9062: Projeto e execução de estruturas de concreto pré-moldado. Rio de Janeiro, 2006. 42 p.

[15] ASSOCIAÇÃO BRASILEIRA DE NORMAS TÉCNICAS. NBR 8522: Concreto - determinação dos módulos estáticos de elasticidade e de deformação e da curva tensão-deformação. Rio de janeiro, 2003. 9 p.

[16] ASSOCIAÇÃO BRASILEIRA DE NORMAS TÉCNICAS. NBR 5739: Concreto - ensaio de compressão de corpos-de-prova cilíndricos. Rio de Janeiro, 1994. 4 p.

[17] CARPINTERI, A., CARMONA, J. R., VENTURA, G. "Failure mode transitions in reinforced concrete beams - part 2: experimental tests”, ACI Structural Journal, v. 108, n. 3, pp. 286-293, Mai-Jun. 2011.

[18] PIRES, E. F. C. Propriedades de fratura e análise não-linear de vigas pré-moldadas de concreto geopolimérico: estudo comparativo, Tese de D.Sc., UFF, Niterói, RJ, Brasil, 2015.

[19] PACHECO, T. M., LIMA, J. M. F., LIMA, P. R. L. "Influência do modelo de fissuração na modelagem em elementos finitos de vigas de concreto armado", Science \& Engineering Journal, v. 22, n. 2, pp. 57 - 63 , Jul.-Dez. 2013. 